Island Studies Journal, Vol. 9, No. 2, 2014, pp. 183-190

\title{
Guest Editorial Introduction: Understanding island cities
}

\author{
Adam Grydeh $\phi j$ \\ Island Dynamics \\ Denmark \\ agrydehoj@islanddynamics.org
}

\begin{abstract}
Island studies research has traditionally focused on relatively rural, peripheral, and isolated communities, yet island cities (strongly urbanized small islands or archipelagos or major population centres of large islands or archipelagos) also represent an important research area. Island spatiality has a host of historical and continuing effects on urban development, influencing urban densification and agglomeration, zonal differentiation, and neighbourhood formation in cities both big and small. This special section of Island Studies Journal includes papers on the island cities and urban archipelagos of Peel (Isle of Man, British Isles), Nuuk (Greenland), Palma de Majorca (Spain), Belize City (Belize), and Mumbai (India). The Island Cities and Urban Archipelagos research network seeks to help enrich wider island studies scholarship and contribute to introducing the island dimension to urban studies.
\end{abstract}

Keywords: island cities, island spatiality, island studies, urban archipelagos, urban development, urban studies

(C) 2014 - Institute of Island Studies, University of Prince Edward Island, Canada.

\section{Introduction}

There is a tendency both within island studies and the wider cultural sphere to associate islands with rural, peripheral, and isolated landscapes and communities. Despite this, few scholars would actually claim that rurality, peripherality, and isolation are necessary characteristics of islands; focus is instead often placed on demonstrating how apparently rural, peripheral, and isolated places in fact confound expectations, on how island realities differ from island tropes. Such research in many ways lies at the heart of the island studies project. But this also risks deceiving us, as island researchers, into artificially limiting the category of 'islands' and the characteristics of 'islandness'. For, if we wish to argue for islands as the 'focus' of research rather than as mere metaphorical and symbolic springboards for other concerns (Ronström, 2013), it does us no favours to restrict our understanding of 'real islands' to only those places that (illusively) match the popular island tropes. Indeed, it is perplexing that island studies has largely ignored what must - by measures of population size, economic heft, and political influence - be the most significant type of island community of all: island cities. 


\section{A. Grydeh $\phi j$}

\section{Kinds and types}

There are different kinds of island cities, most obviously: 1) strongly urbanized small islands and archipelagos; as well as: 2) major population centres located on largely rural islands or archipelagos. Examples of the former include New York City, Portsmouth, and Singapore while examples of the latter include Antananarivo, Reykjavik, and Taipei. Absolute measures of population size are not key determinants of city status: Venice is not a particularly large city by world standards, but it is surely an island city on account of its strongly urbanized archipelago. Similarly, in some contexts, Nuuk would be little more than a small town, but in the context of the lightly populated expanse of Greenland, it takes on the role of an island city. Some cities can represent both kinds of island cities simultaneously: Thus, Malé is at once a highly dense island city and the major population centre of the Republic of the Maldives as a whole. By the same token, Copenhagen both contains neighbourhoods located on small islands (Amager, the islands of Christianshavn, Kastellet, Slotsholmen, the city centre in general, etc.) and is the major population centre of a larger island (Zealand) (Figure 1).

\section{Figure 1: Map of Copenhagen, mid-19 ${ }^{\text {th }}$ Century.}

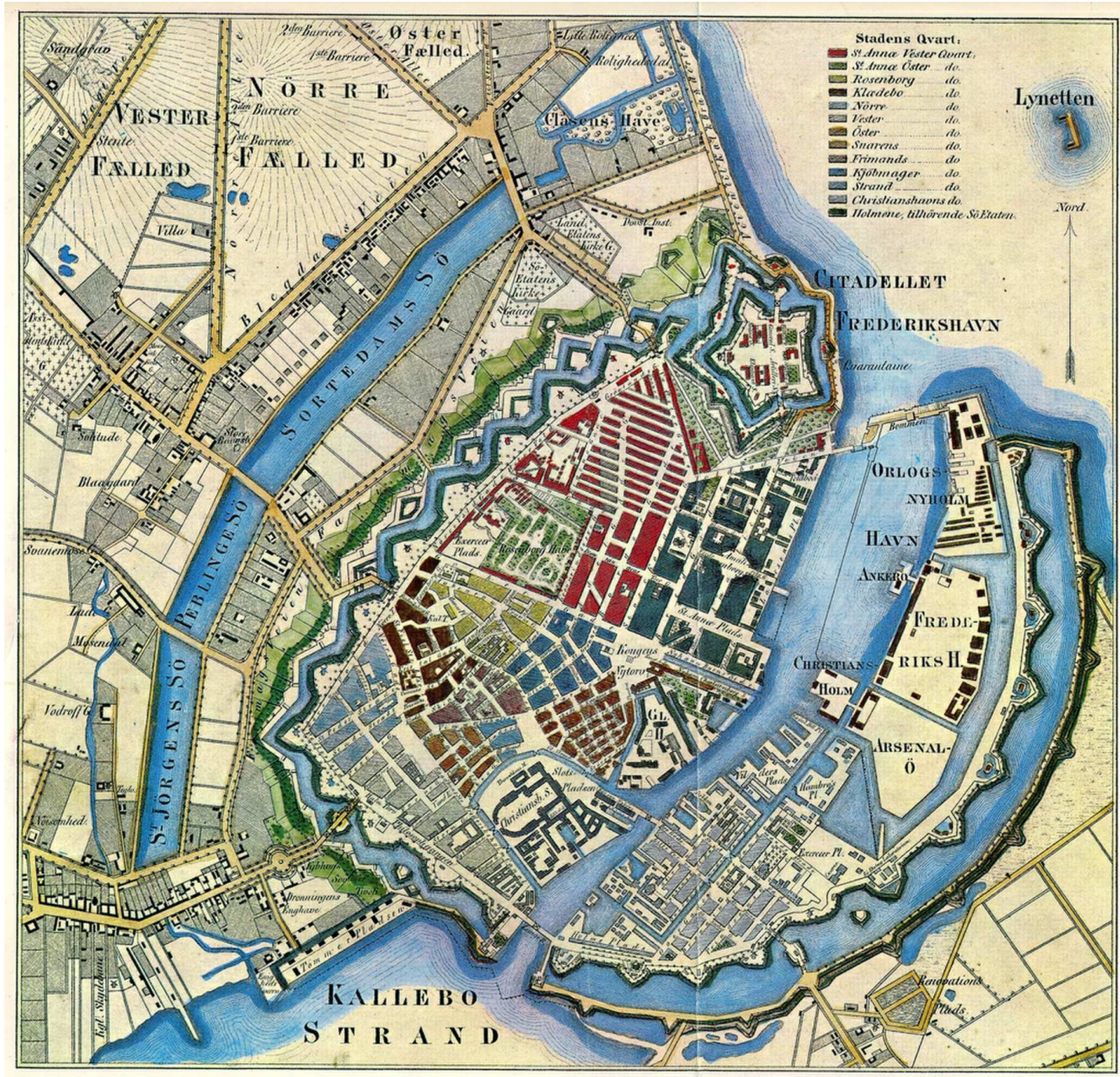

Source: http://commons.wikimedia.org/wiki/File:Copenhagen_circa_1850.jpg 
It is furthermore useful to consider cities that developed substantially on one or more small islands but have since expanded to such an extent as to no longer be popularly associated with islands at all, such as Paris and Strasbourg. Major population centres of larger islands and archipelagos are in some respects self-evident; yet, once one begins looking for them, densely urbanized small islands start materializing all around us as well, including: Abu Dhabi, Amsterdam, Bruges, Florianópolis, Gothenburg, Hong Kong, Lagos, Leiden, Mombasa, Miami Beach, Montreal, Mumbai, St Petersburg, Stockholm, Tromsø, Xiamen, and countless other major national or regional centres.

From a global historical perspective, larger islands that are sufficiently populated will generally tend to develop one or more population centres. In contrast, the development of densely urbanized small islands has generally been occasioned by attempts to create either: 1) a spatially bounded and easily defensible seat of power (such as Tenochtitlan in present-day Mexico City and on the 'castle islands' of Copenhagen and Malmö); or 2) a trading post with access into an economically organized mainland interior, such as the colonial island city outposts of Hong Kong, Macau, and Shamian (in Guangzhou) in China's Pearl River Delta.

\section{Shift required}

The study of urban areas on islands nevertheless requires something of a shift in mindset for those active in island studies. It requires researchers to broaden their internal definitions as to what it means to be an island. Recent debate within the field - diverse though its conclusions have been - has suggested that islands are fundamentally cultural phenomena, a combination of human experience and physical space (Hay, 2013; Pugh, 2013; Fleury, 2013; Hayward, 2012a; Baldacchino, 2012; Pungetti, 2012). It is we - humans - who imbue a place with the quality of islandness. Nor are scholars immune from such 'islanding': they too turn places - especially rural, peripheral, and isolated places - into islands (Boyd Goldie, 2011).

Scholars also sometimes choose not to turn places into islands. Since I personally began researching island cities per se, I have encountered a great deal of scepticism. 'Yes,' I am constantly told, 'that city is technically an island. But it's not really an island.' An island, in this view, does not have bridges and - just as importantly - does not have many people. Even within the island studies community, the general encouragement I have received for urban island studies is sometimes tempered by a certain reticence, for the study of island cities represents a challenge to how we study islands in general.

Urban communities are not entirely absent from explicitly island scholarship (for instance, Bernardie-Tahir \& Schmoll, 2014; Guerrero, 2013; Godenau \& Nuez Yánez, 2013; Hayward, 2012). Yet within island studies, the city is so often exceptional or a deviation from the true nature of the island. We might not wish to argue that New York City or Singapore are any less archipelagos than Shetland or Vanuatu, but there is a tendency to assume that places like New York City and Singapore are less island-like than places like Shetland and Vanuatu, that the true character of islandness lies in rural, remote, and out-of-the-way places. In this, we enter into a variety of the same romanticising, othering, mainland-centric discourse that island scholars have otherwise spent so much energy disavowing. It is not that we are wrong to identify islands - and for that matter, cities - as cultural phenomena. The issue is instead that, if we are to set 'islands' as our focus of inquiry, it is advisable to take a critical look at and discover an intellectual rationale for either including or not including urban island studies within our field of research. 


\section{A. Grydeh $\phi j$}

\section{Rationale}

I will leave it to others to argue against the inclusion of island cities within the field of island studies should they so desire. Instead, I will briefly set out reasons why island cities ought to be included, bearing in mind that the field has hitherto displayed so little urgency on this count. This rationale for studying cities on islands and islands in cities can be divided into two basic arguments: 1) we can learn about wider urban development processes; and 2) we can learn about wider island development processes.

\section{Learning about urban processes}

The spatio-temporally conditioned patterns of island city origins suggest that island status had a number of particular effects on urban development in former times. Indeed, it may be easier to imagine the effect that islandness has historically had on urban development than to conceive of effects today. After all, bridges now connect many densely urbanized small islands to mainlands and other islands, while airports and container ships mean that cities on large islands and archipelagos now interact differently with the surrounding world. Yet, far from declining in importance, major population centres on larger islands and archipelagos have often increased in prominence. Changing transport technologies and global trade have not only enhanced connections between smaller island communities and the outside world. They have also made smaller communities more dependent on the hub and gateway functions of major population centres, fundamentally changing rural-urban relationships on large islands and archipelagos such as Iceland and Taiwan.

In the case of densely urbanized small islands, island status can also be of both historical and continuing importance. Thus, for instance, Macau became a Portuguese trading post because it was an archipelago near an economically organized mainland interior. However, the acute land scarcity arising from its island status contributed - and still contributes - to intensive urban densification and land reclamation processes. Miniscule Macau is an extreme example, but in megacities like Guangzhou, Manila, Mumbai, and Tokyo, the urban challenges brought about by island spatiality are, in a sense, scaled up in light of such cities' enormous populations. Reflection upon the fact that New York City is primarily archipelagic goes a long way toward explaining the much-discussed question as to why New York City has by far the greatest population density of any American city. Such densification is, furthermore, cumulative as agglomeration processes feed upon themselves: Singapore is an international trading hub not just because of its strategic location but also because, in combination with its strategic location, Singapore's archipeligacity prompted the development of spatially dense networks of industry, infrastructure, and knowledge.

Islands result in more than just urban densification however. The various distinct neighbourhoods of Copenhagen, for example, mirror the city's archipelagic spatial fragmentation (as shown in Figure 1 above) even though the bodies of water separating them were never particularly difficult to cross. Even today, as the small islands comprising Copenhagen's Holmen area undergo deindustrialization and demilitarization, they are being repurposed for experimental or explicitly distinctive business, leisure, and residential use, 
relative to the generally more mundane uses applied to newly available land in less obviously insular contexts within the city. This belongs to a wider process of urban zonal differentiation following the straightforwardly delineated spaces of islands within cities. Thus, for instance, some island spaces are allowed to be (visually) 'frozen in time' by the modern taste for heritagization (as on Christianshavn in Copenhagen, Gamla Stan in Stockholm, and Île de la Cité in Paris). The creation of such island heritage zones partly protects historical buildings, cityscapes, and ways of life from the encroachment of modern urban functions. However, it also protects the needs of the modern city from unlimited demands for urban built and cultural heritage preservation. It is thus that many cities continue to fracture and splinter along island lines. Lamma (Hong Kong), Pulau Ubin (Singapore), Randalls and Wards Islands (New York City), and the Toronto Islands (Toronto) provide contained leisure and managed nature spaces within the city. Chek Lap Kok (Hong Kong), Odaiba (Tokyo), and Papirøen (Copenhagen) offer bounded spaces for social and economic innovation. Eko Atlantic (Lagos), Funtasy Island (Singapore/Batam), and the Sunset Islands (Miami Beach) represent secessionary residential enclaves.

In other words, island spatiality exerts developmental influence in urban contexts not just historically but also in terms of development and redevelopment of cities and neighbourhoods today, even in the presence of bridges, ferries, trains, and buses. An 'island approach' to places like New York City and Copenhagen is not, of course, the only possible or the only desirable approach. However, it is an approach that can contribute to our knowledge as to why such cities develop in the ways they do.

\section{Learning about island processes}

By considering island cities, we can gain understanding of other aspects of islandness. This includes greater clarity regarding a number of the trickiest considerations within the field of island studies, namely to what extent some of the impacts popularly attributed to islandness are in fact attributable to small economic and population size in general, rather than to islandness in particular (Baker, 1992). Island studies has been preoccupied with proving that islandness is not just about smallness and isolation: What better proof can be found than the knowledge that island status has certain effects even on non-isolated communities with large economies and populations? Island cities research thus has the potential to strengthen the argument in support of island studies as a valid and legitimate field of research.

Finally, unless we are willing to take an urban approach to island population centres, we risk ignoring internal differences within larger islands and archipelagos as well as differences between kinds of islands and archipelagos. One of the future tasks for island studies must be to subject places like Port Vila (Vanuatu) and Lerwick (Shetland) to explicitly urban analyses rather than to content itself with accounts that gloss over intra-island and intraarchipelago urban-rural relations, that unintentionally anchor the field in the old tropes of island-mainland relations, and that marginalize in their very effort to empower. This is a sin of which many of us in the island studies community have surely been guilty (e.g. Grydehøj, 2013). By embracing the diversity of islands and island communities, we can more ably analyze the dynamics within and between them. 


\section{A. Grydeh $\phi j$}

\section{Content review}

This special island cities section of Island Studies Journal represents a first step at responding to the challenge of a new urban island studies. The six papers presented here consider a diverse mix of island cities from around the world. Tutt (2014) uses the example of the ancient town of Peel, Isle of Man, British Isles, to discuss what it means to be an island city. Grydehøj (2014) considers how economic, political, cultural, and historical factors have caused Nuuk to develop as the 'centre' of Greenland. Picornell (2014) examines how the city of Palma has been cast as a monster threatening the 'authentic' culture of Spain's Balearic Island of Majorca. Pons, Rullan, and Murray (2014) also consider the Balearic Islands, but they do so through a quantitative study of how tourism urbanization processes are linked to transport and infrastructural conditions. Pigou-Dennis \& Grydehøj (2014) question what it means to be an island through a comparison of the historical development of Europe's island cities and the urban archipelago of Belize City, Belize. Finally, Swaminathan (2014) analyzes how archipelagic spatiality affects mindscapes of power and value in Mumbai, India.

This special section is a small part of a wider effort to create links between island studies and urban studies. Under the auspices of Island Dynamics, the new Island Cities and Urban Archipelagos research network is engaged in establishing urban island studies as a field of research (ICUA, 2014). The first ICUA conference was held in Copenhagen in October 2014, featuring around 75 presentations on cultural, political, environmental, architectural, and economic aspects of urban island communities. A second ICUA conference is planned for Hong Kong in March 2016. The coming years will also see a number of journal special issues devoted to urban island studies. We hope that this new research area will help enrich wider island studies and contribute to introducing the island dimension to urban studies.

\section{References}

Baker, R. (1992) Scale and administrative performance: the governance of small states and microstates. In R. Baker (Ed.), Public administration in small and island states (pp. 5-25). West Hartford CT: Kumarian Press.

Baldacchino, G. (2012). The lure of the island: a spatial analysis of power relations. Journal of Marine and Island Cultures, 1(2), 55-62.

Bernardie-Tahir, N., \& Schmoll, C. (2014). Opening up the island: a 'counter-islandness' approach to migration in Malta. Island Studies Journal, 9(1), 43-56.

Boyd Goldie, M. (2011). Island theory. In M. McCusker \& A. Soares (Eds.), Islanded identities: Constructions of postcolonial cultural insularity (pp. 1-40). Amsterdam: Rodopi. 
Fleury, C. (2013). The island/sea/territory relationship: towards a broader and three dimensional view of the aquapelagic assemblage. Shima: The International Journal of Research into Island Cultures, 7(1), 1-13.

Godenau, D., \& Yánez, J.S.N. (2013). Feeding two million residents and ten million tourists: food (in)sufficiency in the Canary Islands. Shima: The International Journal of Research into Island Cultures, 7(2), 17-38.

Grydehøj, A. (2014). Constructing the centre on the periphery: policies and processes of urban development in Nuuk, Greenland. Island Studies Journal, 9(2), 205-222

Grydehøj, A. (2013). Challenges to local government innovation: legal and institutional impediments to the exercise of innovative economic development policy by subnational jurisdictions. European Journal of Spatial Development, 50, 1-21.

Guerrero, P. (2013). A story told through Plena: claiming identity and cultural autonomy in the street festivals of San Juan, Puerto Rico. Island Studies Journal, 8(1), 165-178.

Hay, P. (2013). What the sea portends: a reconsideration of contested island tropes. Island Studies Journal, 8(2), 209-232.

Hayward, P. (2012). Aquapelagos and aquapelagic assemblages. Shima: The International Journal of Research into Island Cultures, 6(1), 1-11.

Hayward, P. (2012). Merlionicity: the twenty first century elaboration of a Singaporean symbol. Journal of Marine and Island Cultures, 1(2), 113-125.

ICUA (2014). Island cities and urban archipelagos. Retrieved from http://www.islandcities.org

Picornell, M. (2014). Insular identity and contemporary urban contexts: representations of the local in the construction of an image of Palma (Majorca, Balearic Islands). Island Studies Journal, 9(2), 223-238.

Pigou-Dennis, E., \& Grydehøj, A. (2014). Accidental and ideal island cities: islanding processes and urban design in Belize City and the urban archipelagos of Europe. Island Studies Journal, 9(2), 259-276.

Pons, A., Rullan, O., \& Murray, I. (2014). Tourism capitalism and the urbanization of the Balearic Islands: tourist accommodation diffusion in the Balearics, 1936-2010. Island Studies Journal, 9(2), 239-258.

Pugh, J. (2013). Island movements: thinking with the archipelago. Island Studies Journal, $8(1), 9-24$.

Pungetti, G. (2012). Islands, culture, landscape and seascape. Journal of Marine and Island Cultures, 1(2), 51-54. 


\section{A. Grydeh $\phi j$}

Swaminathan, R. (2014). The epistemology of a sea view: mindscapes of space, power and value in Mumbai. Island Studies Journal, 9(2), 277-299.

Tutt, P.A. (2014). Defining the island city: ancient right versus modern metropolis, as considered at Peel, Isle of Man. Island Studies Journal, 9(2), 196-204. 